\title{
Makna Shirat, Sabil dan Thariq Dalam Tafsir Al-Misbah Serta Implementasinya Dalam Kehidupan
}

\author{
Ebing Karmiza \\ STIT Daarul Hikmah \\ Ekarmiza92@gmail.com
}

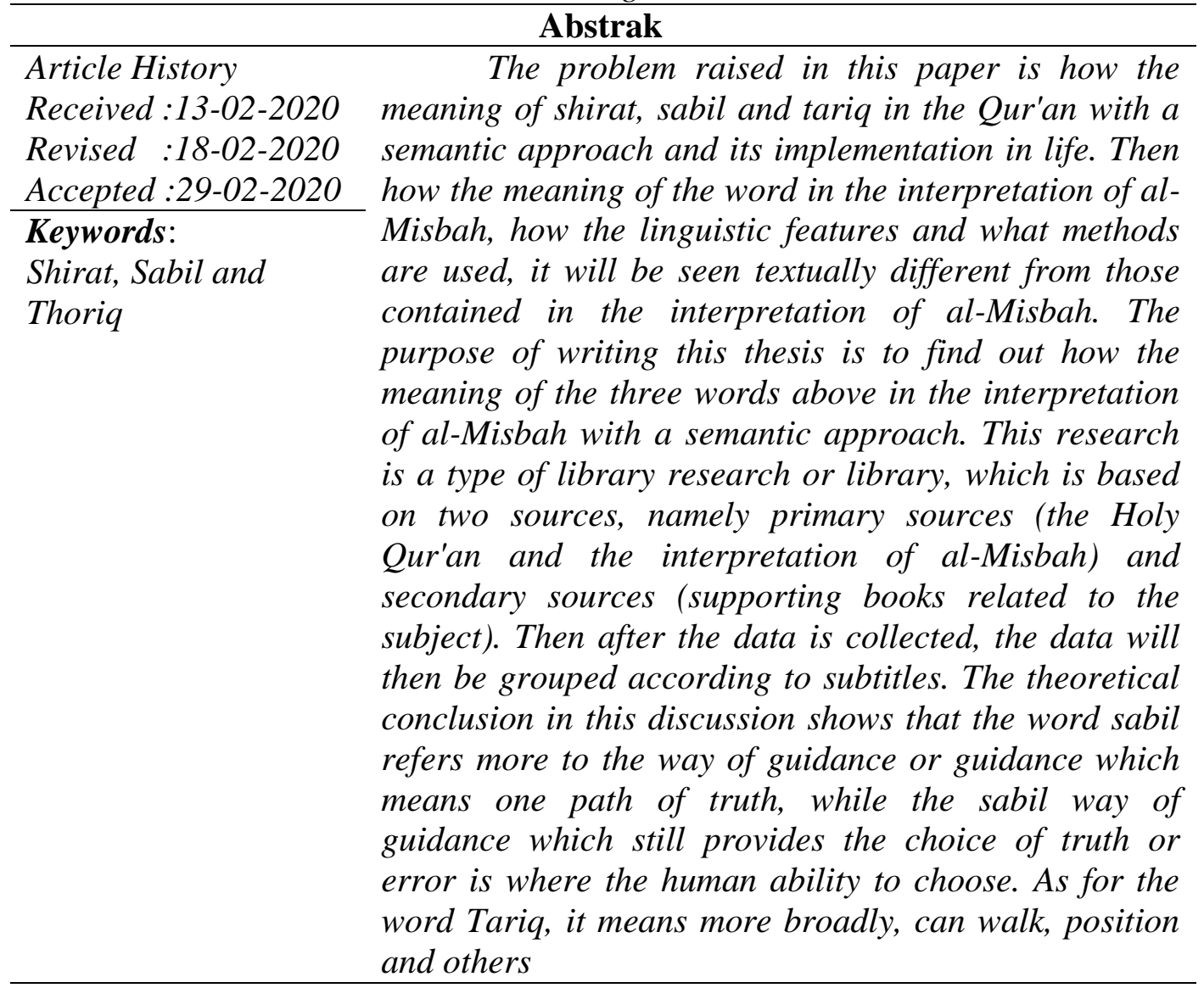

\section{Pendahuluan}

Al-Qur'an diturunkan dengan mengemban tiga fungsi, yaitu sebagai huda atau petunjuk bagi manusia, kedua sebagai bayyinah atau penjelas mengenai petunjuk itu serta sebagai furqon atau pembeda antara yang haq dan bathil (Shihab, 2007: 10). Kitab suci al-Qur'an sebagai mukjizat terbesar Nabi Muhammad Saw memiliki keistimewaan-keistimewaan di dalamnya, mulai dari susunan bahasa, gaya bahasa yang digunakan dan penggunaan kata yang sama akan tetapi digunakan di banyak tempat dengan tujuan yang berbeda dan juga sebaliknya ada kata-kata dengan lafaz yang berbeda akan tetapi menunjukkan satu arti yang sama. Salah satunya adalah arti kata shiraat, sabil dan thariq ketiganya mempunyai arti yang sama yaitu jalan. Akan tetapi dalam penggunaannya tidak lah sama, sebagai contoh kata sabil sering bersamaan dengan kata Allah Swt yakni sabiilillah, adapun kata shiraat sering bersamaan dengan kata mustaqim, salah satunya dalam surat Al-Fatihah kata shiraat al-mustaqim, adapun kata thariq kadang bergandengan dengan kata mustaqim dan kadang dengan kata lainnya seperti kata jahannam. 
Dalam tafsir "An-Nur” Karya Hasbiy Ash- Shiddiqiy makna shiraat dalam ayat di atas adalah jalan yang lempang, ialah sekumpulan pekerjaan yang menyampaikan kita kepada kebahagian dunia dan akhirat, yang terdiri dari beberapa aqidah, hukum, adab, dan undang-undang agama, semisal meyakini adanya Allah Swt, mengakui kenabian Nabi dan keadaan-keadaan alam dan masyarakat hidup. Yang dimaksud dengan jalan yang lempang adalah kerena mengingat, bahwa apabila kita bermaksud sampai ketempat yang dituju haruslah dia menjalani jalan yang dituju itu( Ash-Siddiqiy, 1965: 42) Menurut Muhammad Syaltut dalam "Tafsir Al-Qur'anul Karim" menjelaskan bahwa kata shiraat almustaqim bermakna kumpulan semua jalan manusia menuju kebahagian dunia dan akhirat. Jalan tersebut meliputi soal aqidah ( keyakinan ), akhlak dan hukum, baik dari segi ilmu maupun amaliyah. Itulah jalan Islam, yang mengakhiri semua risalah Ilahi serta menjadikan al-Qur'an sebagai konstitusinya. (Syaltut, 1989: 66) Artinya : "Bagaimanakah kamu (sampai) menjadi kafir, Padahal ayat-ayat Allah dibacakan kepada kamu, dan Rasul-Nya pun berada di tengah-tengah kamu? Barangsiapa yang berpegang teguh kepada (agama) Allah, Maka Sesungguhnya ia telah diberi petunjuk kepada jalan yang lurus." ( Q. S. Ali-Imran : 101)

Adapun kata sabil berarti jalan atau cara menuju Allah Swt (Mujieb, 2009: 430). Dan terdapat dalam beberapa surat di antara, dalam Q. S An-Nisa : 100 dan Q. S. At-Taubah: 93 Artinya : "Barangsiapa berhijrah di jalan Allah, niscaya mereka mendapati di muka bumi ini tempat hijrah yang Luas dan rezki yang banyak. Barangsiapa keluar dari rumahnya dengan maksud berhijrah kepada Allah dan Rasul-Nya, kemudian kematian menimpanya (sebelum sampai ke tempat yang dituju), Maka sungguh telah tetap pahalanya di sisi Allah. dan adalah Allah Maha Pengampun lagi Maha Penyayang.” ( Q. S. An-Nisa: 100) Artinya : "Sesungguhnya jalan (untuk menyalahkan) hanyalah terhadap orangorang yang meminta izin kepadamu, Padahal mereka itu orang-orang kaya. mereka rela berada bersama orang-orang yang tidak ikut berperang dan Allah telah mengunci mati hati mereka, Maka mereka tidak mengetahui (akibat perbuatan mereka).” ( Q. S. At-Taubah : 93 ).

Dalam tafsir al-Maraghi kata sabil yang terdapat dalam Q. S At-Taubah: 93, menunjukkan arti secara umum atau besifat umum dan menyeluruh kepada setiap orang yang melakukan segala perbuatan baik dan takwa (Al-Maraghi, 1992: 311). Sedangkan dalam tafsir al-Misbah kata sabil dalam ayat tersebut menunjukkan kekuasaan wewenang, kerena jalan disana adalah jalan yang bisa mengantarkan siapa saja yang memilikinya dan mampu menjatuhkan sanksi dan melaksanakan kebijaksanaan (Shihab, 2012: 205). Kata Thariq sendiri salah satunya terdapat dalam Q. S. An-Nisa : 168-169 dan Q. S Al-Ahqof : 30 Artinya : "Sesungguhnya orang-orang yang kafir dan melakukan kezaliman, Allah sekali-kali tidak akan mengampuni (dosa) mereka dan tidak (pula) akan menunjukkan jalan kepada mereka." (Q. S. An-Nisa : 168 ) Artinya : "kecuali jalan ke neraka Jahannam; mereka kekal di dalamnya selama-lamanya. dan yang demikian itu adalah mudah bagi Allah." ( Q. S. An-Nisa: 169)

Dalam tafsir al-Misbah kata (ألصِّرَأطَا) Ash-Shiraat terambil dari kata saratha سرط dan karena huruf (w) dalam kata ini bergandengan dengan

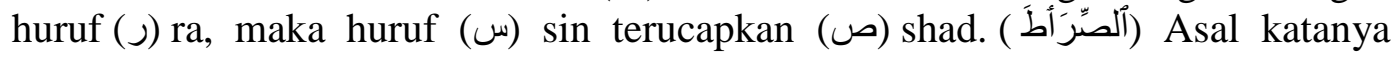
sendiri bermakna "menelan". Jalan yang lebar dinamai shiraat karena sedemikian lebarnya sehingga ia bagaikan menelan pejalan yang lalu lalang disana, 
sebagaimana telah dijelaskan di atas dalam buku " Lentera Al-Qur'an " (Shihab, 2008: 52). Kata shiraat ditemukan dalam al-Qur'an sebanyak 45 kali semuanya berbentuk tunggal, selebihnya dirangkaikan dengan berbagai kata seperti assawiy, mustaqim, dan al-jahim. Bila shiraat dinisbatkan kepada sesuatu, maka penisbahannya adalah kepada Allah Swt. seperti shiraataka (jalan-Mu) atau shiraati (jalan-Ku) dan lain-lain, atau kepada orang-orang mukmin yang mendapat anugerah nikmat ilahi seperti dalam ayat al-fatihah ayat 7.

Shiraat berbeda dengan sabil yang juga sering diterjemahkan dengan "jalan." Kata sabil ada yang berbentuk jamak seperti subulus salaam (jalan-jalan kedamaian), ada pula yang tunggal, dan ini ada yang dinisbahkan kepada Allah seperti sabiilillaah atau kepada orang yang bertaqwa seperti sabiil al-muttaqiin, dan ada juga yang dinisbahkan kepada orang orang yang berdosa seperti sabiil atthaaghuut. Makna ash-Shiraat hanya satu dan selalu bersifat benar dan hak, berbeda dengan sabiil yang bisa benar bisa salah, bisa merupakan jalan orangorang yang bertaqwa, bisa juga jalan orang-orang yang durhaka. Sedangkan kata thariq selain bermakna jalan ada yang mengartikan sebagai kedudukan, panutan dan bermakna agama Islam.

Melihat penjelasan di atas, baik dalam buku maupun kitab tafsir, penjelasan M. Quraish Shihab lebih luas dan mendetail, menarik kiranya untuk dikaji lebih mendalam bagaimana makna shiraat, sabil dan thariq dalam tafsir al-Misbah dengan mengacu pada pandangan M. Quraish Shihab. Kemudian tafsir al-Misbah memiliki kekayaan bahasa yang sangat baik dalam menjelaskan maksud suatu ayat, sebagaimana seperti yang telah dijelaskan di atas, selain daripada itu tafsir al-Misbah juga membandingkan berbagai pendapat Mufassir abaik klasik maupun modern. Kerena beberapa kelebihan tafsir al-Misbah inilah menurut penulis, sangat menarik jika dibahas lebih lanjut. Untuk mengkaji ketiga makna di atas akan sangat menarik menggunakan studi linguistik, salah satu cabang linguistik yang mempelajari makna pada sebuah kata adalah semantik. Semantik diartikan oleh ahli bahasa sebagai kajian analitik terhadap istilah-istilah kunci suatu bahasa dengan seuatu pandangan yang akhirnya sampai pada pengertian konseptual dari masyarakat pengguna bahasa tersebut. Pandangan ini tidak hanya sebagai alat bicara dan berfikir, tetapi lebih penting lagi mengenai pengonsepan dan penafsiran dunia yang melingkupinya (Setiawan, 2005: 166).

Menurut Toshihiko Izutsu yang merupakan pakar semantik al-Qur'an pada era modern dan juga yang pertama kali menggunakan atau mengaplikasikan semantik dalam memknai kata-kata dalam al-Qur'an. Menurut Toshiko Izutsu semantik dalam tafsir adalah kajian analitik terhadap istilah-istilah kunci suatu bahasa dengan suatu pandangan yang akhirnya berusaha menyikap pada pandangan konseptual pandangan dunia masyarakat yang menggunakan bahasa itu, tidak hanya sebagai alat bahasa dan berfikir, tetapi yang paling penting adalah bagaimana mengkonsepkan sesuatu dengan penafsiran yang melingkupinya (Izutsu: 1997: 2). Dan beliau juga berusaha menyikap pandangan dunia al-Qur'an melalui analisis semantik terhadap materi di dalam al-Qur'an sendiri, yakni kosa kata atau istilah-istilah penting yang banyak digunakan oleh al-Qur'an (Izutsu: 1997: 2).

Untuk itu penulis berpendapat bahwa mengkaji makna ketiga kata tersebut berdasarkan pandangan M. Quraish Shihab dengan metode analitis semantik sangat menarik untuk dikaji. 


\section{Pembahasan}

\section{Landasan Teori}

Untuk mempermudah megetahui jumlah ayat-ayat yang terdapat kata Shiraat, Sabil dan Thariq, maka berikut ini akan disusun jumlah ayat-ayat tersebut berdasarkan mu'jam al-Qur'an. Dalam al-Qur'an jumlah kata shiraat ada 43 ayat, kata sabil ada 119 ayat dan thariq ada 9 ayat (Baqy, 1981: 407). Adapun untuk mengklasifikasi ayat-ayat berdasarkan makiyah dan madaniyah yakni melihat daripada surahnya apakah tergolong ke madaniyah atau madaniyah dan yang menjadi acuan adalah al-Qur'an versi departemen agama republik Indonesia.

\begin{tabular}{|c|c|c|c|c|}
\hline \multicolumn{5}{|c|}{ Shiraat } \\
\hline \multirow[t]{2}{*}{ No } & \multirow[t]{2}{*}{ Nama Surat } & \multirow[t]{2}{*}{ Ayat } & \multicolumn{2}{|c|}{ Keterangan } \\
\hline & & & Makiyah & Madaniyah \\
\hline 1 & Al-Fathihan & 6 dan 7 & Makiyah & \\
\hline 2 & Al-Baqarah & 142 dan 213 & & Madaniyah \\
\hline 3 & Ali-Imran & 51 dan 101 & & Madaniyah \\
\hline 4 & Al-Maidah & 16 & & Madaniyah \\
\hline 5 & Al-An'am & $39,87,126$ dan 161 & Makiyah & \\
\hline 6 & Al-A'rof & 86 & Makiyah & \\
\hline 7 & Yunus & 25 & Makiyah & \\
\hline 8 & Hud & 56 & Makiyah & \\
\hline 9 & Ibrahim & 1 & Makiyah & \\
\hline 10 & Al-Hijr & 41 & Makiyah & \\
\hline 11 & An-Nahl & 76 dan 121 & Makiyah & \\
\hline 12 & Maryam & 36 & Makiyah & \\
\hline 13 & Toha & 135 & Makiyah & \\
\hline 14 & Al-Haj & 24 dan 54 & & Madaniyah \\
\hline 15 & Al-Mu'minun & 73 dan 74 & Makiyah & \\
\hline 16 & Nur & 46 & & Madaniyah \\
\hline 17 & Saba' & 6 & Makiyah & \\
\hline 18 & Yasin & 4,61 dan 66 & Makiyah & \\
\hline 19 & Shoffat & 23 dan 118 & Makiyah & \\
\hline 20 & Shod & 22 & Makiyah & \\
\hline 21 & Asy-Syura' & 53 dan 53 & Makiyah & \\
\hline 22 & Az-Zukhruf & 43,61 dan 64 & Makiyah & \\
\hline 23 & Al-Mulk & 22 & Makiyah & \\
\hline 24 & An-Nisa & 68 dan 175 & & Madaniyah \\
\hline 25 & Maryam & 43 & & Madaniyah \\
\hline 26 & Al-Fath & 2 dan 20 & & Madaniyah \\
\hline & Jummlah & & & \\
\hline
\end{tabular}


Sabil

\begin{tabular}{|c|c|c|c|c|}
\hline \multirow[t]{2}{*}{ No } & \multirow[t]{2}{*}{ Nama Surat } & \multirow[t]{2}{*}{ Ayat } & \multicolumn{2}{|c|}{ Keterangan } \\
\hline & & & Makiyah & Madaniyah \\
\hline 1 & Al-Baqarah & $\begin{array}{l}108,154,177,190,195,215,21 \\
7,218,244,246,261,262, \text { dan } \\
273\end{array}$ & & Madaniyah \\
\hline 2 & Ali-Imran & $\begin{array}{l}13,75,99,146,157,167 \\
\text { dan169 }\end{array}$ & & Madaniyah \\
\hline 3 & An-Nisa & $\begin{array}{l}36,43,44,74,75,76,84,89,94,9 \\
5,100,115,160,167\end{array}$ & & Madaniyah \\
\hline 4 & Al-Maidah & $12,54,60$, dan 77 & & Madaniyah \\
\hline 5 & Al-An'am & 55 dan 116 & Makiyah & \\
\hline 6 & Al-A'rof & $45,86,142,146$ & Makiyah & \\
\hline 7 & Al-Anfal & $36,41,47,60,72,74$ & & Madaniyah \\
\hline 8 & Ath-Taubah & $\begin{array}{l}19,20,34,38,41,60,81,91,93,1 \\
11,120\end{array}$ & & Madaniyah \\
\hline 9 & Yunus & 89 & Makiyah & \\
\hline 10 & Hud & 19 & Makiyah & \\
\hline 11 & Ar-Ra'du & 33 & Makiyah & \\
\hline 12 & Ibrahim & 3 & Makiyah & \\
\hline 13 & Al-Hijr & 76 & Makiyah & \\
\hline 14 & An-Nahl & $9,88,94,125$ & Makiyah & \\
\hline 15 & Al-Isro & 26 & Makiyah & \\
\hline 16 & Al-Haj & $9,25,58$ & & - \\
\hline 17 & An-Nur & 22 & Makiyah & \\
\hline 18 & Al-Furqon & 17 & Makiyah & \\
\hline 19 & An-Naml & 24 & Makiyah & \\
\hline 20 & Al-Qashash & 22 & Makiyah & \\
\hline 21 & Al-Ankabut & 29,38 & Makiyah & \\
\hline 22 & Ar-Rum & 38 & Makiyah & \\
\hline 23 & Luqman & 6,15 & Makiyah & \\
\hline 24 & Al-Ahzab & 4 & & Madaniyah \\
\hline 25 & Shod & 26 & Makiyah & \\
\hline 26 & Fathir & $11,29,37,38$ & Makiyah & \\
\hline 27 & Asy-Syuro & $41,42,44,46$ & Makiyah & \\
\hline 28 & Az-Zukhruf & 37 & Makiyah & \\
\hline 29 & Muhammad & $1,4,32,34,38$ & & Madaniyah \\
\hline 30 & Al-Hujurot & 15 & Makiyah & \\
\hline 31 & Al-Hadid & 10 & & Madaniyah \\
\hline 32 & Al-Mujadilla & 16 & & Madaniyah \\
\hline 33 & Al-Hasyr & 7 & & Madaniyah \\
\hline 34 & Mumtahanah & 1 & & Madaniyah \\
\hline 35 & Ash-Shof & 11 & & Madaniyah \\
\hline 36 & Munafiqun & 2 & & Madaniyah \\
\hline 37 & Muzammil & 20 & Makiyah & \\
\hline 38 & Al-Insan & 3 & & Madaniyah \\
\hline 39 & A'basa & 20 & Makiyah & \\
\hline
\end{tabular}


Thariq

\begin{tabular}{|l|l|l|l|l|}
\hline No & Nama Surat & Ayat & Keterangan & \\
\cline { 4 - 5 } & & & Makiyah & Madaniyah \\
\hline 1 & An-Nisa & 168,169 & & Madaniyah \\
\hline 2 & Al-Ahqof & 30 & Makiyah & \\
\hline 3 & Toha & $63,77,104$ & & Madaniyah \\
\hline 4 & Al-Jin & 11,16 & Makiyah & \\
\hline 5 & Al-Mu'minun & 17 & Makiyah & \\
\hline & & & & \\
\hline
\end{tabular}

Setelah melihat pengklasifikasian ayat-ayat yang berkenaan dengan ketiga kata di atas, ternyata lebih banyak terdapat pada ayat-ayat makiyah. Kalau melihat karakteristik daripada ayat-ayat makiyah yang mengajak kepada tauhid dan beribadah hanya kepada Allah Swt, pembuktian risalah hari kebangkitan dan pembalasan, hari penyiksaan, surga dan neraka. Peletakan dasar-dasar hokum perundan-undangan Islam dan akhlak mulia yang menjadi dasar terbentuknya suatu masyarakat. Mengisahkan kisah-kisah Nabi dan umat terdahulu, sebagai pelajaran untuk mengetahui bagaimana Nasib orang-orang yang mendustakan agam Allah Swt.

Jadi bisa dipahami bahwa, ternyata ketiga kata di atas lebih banyak menuntun atau mengajak manusia agar tidak menyimpang dari jalan yang benar, dengan memberikan contoh kisah-kisah umat dan Nabi terdahulu dan juga adanya gambaran berupa $A z a b$ yang pedih bagi yang berdusta. Untuk itu salah satu jalannya adalah agar tetap istiqomah pada jalan yang lurus.

\section{Hasil Penelitian}

\section{Makna Shirat, Sabil dan Thariq Dalam Tafsir Al-Misbah}

Dalam tafsir al-Misbah kata sabil maupun thariq tidak diuraikan secara detail dari sudut kebahasaan, berbeda dengan kata shirat yang di uraikan secara detail, untuk lebih jelasnya sebagaimana penjelasan kata shirat dalam Q. S Alfatihah : 6-7. Di dalam ayat tersebut dari sudut padang bahasa kata shirat begitu jelas dan detail dijelaskan oleh beliau. Adapun kata sabil dan thariq tidak demikian, dalam tafsir al-Misbah M. Quraish Shihab menjelaskan makna kata dalam al-Qur'an mulai dari ayat diawal-awal surah yang tercantum kata tersebut.

Memang yang tampak menarik dari tafsir al-Misbah adalah bahwa kata shirat lebih banyak dijelaskan dan secara detail dari pada kata sabil dan thariq, terutama dalam surah al-Fatihah. Seperti yang telah dijelaskan pada bab sebelumnya bahwa hanya tafsir al-Misbah dan beberapa buku karya M. Quraish Shihab yang menjelaskan secara mendetail makna kata shirat, terutama ketika kata shirat tersbeut bersamaan dengan kata al-Mustaqim. Namun setelah penjelasan kata shirat pada surah al-Fatihah, kata shirat pada ayat-ayat dalam surah berikutnya tidak lagi dijelaskan secara mendatail hanya ada beberapa ayat saja kata shirat dijelaskan hanya untuk menjelaskan posisi dan makna kata tersebut pada konteks ayat tersebut, seperti kata shirat dalam Q. S Al-Baqarah : 142

Artinya : Orang-orang yang kurang akalnya diantara manusia akan berkata: "Apakah yang memalingkan mereka (umat Islam) dari kiblatnya (Baitul Maqdis) yang dahulu mereka telah berkiblat kepadanya?" Katakanlah: "Kepunyaan Allah- 
lah timur dan barat; Dia memberi petunjuk kepada siapa yang dikehendaki-Nya ke jalan yang lurus"

Ayat ini hanya menjelaskan makna shirat sebagai jalan agama, yakni bagi siapa yang Allah Swt kehendaki. Namun berbeda dengan Q. S Ali-Imran : 51 Artinya : "Sesungguhnya Allah, Tuhanku dan Tuhanmu, karena itu sembahlah Dia. Inilah jalan yang lurus"

Pada ayat di atas kata jalan yang lurus dijelaskan juga dengan detail dan mempunyai makna yang berarti agama Islam namun dalam konteks ayat ini menekankan pada keluasan agama Islam atau fleksibelitas ajaran agama Islam yang tidak mempersulit pemeluknya.

Berikut melihat kata shirat dalam Q. S Al-A'raf : 86, dalam ayat ini kata shirat tidak bersama dengan kata al-Mustaqim, akan tetapi di awali dengan kata kulli sehingga bisa berarti banyak jalan.

Artinya: "Dan janganlah kamu duduk di tiap-tiap jalan dengan menakut-nakuti dan menghalang-halangi orang yang beriman dari jalan Allah, dan menginginkan agar jalan Allah itu menjadi bengkok. dan ingatlah di waktu dahulunya kamu berjumlah sedikit, lalu Allah memperbanyak jumlah kamu. dan perhatikanlah bagaimana kesudahan orang-orang yang berbuat kerusakan.",

Dalam tafsir Al-Misbah dijelaskan bahwa Allah Swt melarang manusia berbuat kerusakan di muka bumi dan terutama janganlah menghalangi jalan orang-orang yang ingin melewatu jalan kebaikan dunia dan akhirat juga mengingkari jalan Allah Swt agar jalan Allah Swt itu menjadi "bengkok" yakni dengan mencari-cari dalih atau berusaha mencari kelemahannya untuk menanamkan keraguan terhadapnya. Kerena upaya seperti itu bertujuan meminimalisasi jumlah orang-orang beriman (Shihab, 2012: 203). Dalam ayat ini jelas bahwa kata shirat itu tunggal akan tetapi kerena ditambah dengan kata kulli didepannya dia bermakna banyak jalan atau disetiap jalan, lebih tepatnya menghalangi jalan-jalan manusia yang ingin berjalan di jalan Allah Swt. Sama hal nyan dengan ayat yang terdapat dalam Q. S Ibrahim : 1, kata shirat juga berada sendiri tanpa di damping kata al-mustaqim, namun dalam ayat ini lebih daripada fungsi al-Qur'an yang membawa manusia ke jalan Tuhan yang Maha Perkasa dan Terpuji. Artinya : "Alif, laam raa. (ini adalah) kitab yang Kami turunkan kepadamu supaya kamu mengeluarkan manusia dari gelap gulita kepada cahaya terang benderang dengan izin Tuhan mereka, (yaitu) menuju jalan Tuhan yang Maha Perkasa lagi Maha Terpuji."

Pada ayat ini kata shirat dijelaskan lebih panjang dan lebar, mulai dari jumlam kata shirat yang terdapat dalam 45 ayat, dan kata shirat 32 kali bersama dengan kata al-mustaqim, sisanya berdiri sendiri atau bersama kata sawiy, sawa' dan al-jahim. Dan jika kata shirat di nisbahkan kepada sesuatu maka penisbahannya hanya kepada Allah Swt, misalnya shirataka, shiratiy, dan shirat al-Aziz al-Hamid. (Shihab, 2012: 311) Dalam Q. S Toha : 135, kata shirat bersama kata sawiyy yang bermakna sama dengan al-mustaqim yakni lurus, dan juga ditambah dengan kata hadiy yakni petunjuk

Artinya : "Katakanlah: "Masing-masing (kita) menanti, Maka nantikanlah oleh kamu sekalian! Maka kamu kelak akan mengetahui, siapa yang menempuh jalan yang Lurus dan siapa yang telah mendapat petunjuk".

Pada ayat terakhir Q.S Toha ini dalam tafsir Al-misbah, menjelaskan mengenai penantian yang positif bagi orang yang beriman dan penantian negative 
bagi orang musyrik, berita gembira bagi yang beriman dan berita buruk bagi yang tidak beriman, kenapa penantian kerena mereka tidak akan mendapatkan pengetahuan tersebut di dunia, oleh kerena ini di akhirat kelak akan terlihat siapa yang menempuh jalan lurus dan jalan yang sesat (Shihab, 2012: 717). Selanjutnya dijelaskan juga seperti apa orang-orang yang menempuh jalan-jalan yang sesat yang terdapat dalam Q. S Al-Mu'min : 74

Artinya : "Dan Sesungguhnya orang-orang yang tidak beriman kepada negeri akhirat benar-benar menyimpang dari jalan (yang lurus)."

Orang-orang yang durhaka dan tidak takut menghadapi siksa hari kemudian. Ini disebabkan mereka tidak percaya adanya surga dan neraka. Dan sesungguhnya orang-orang yang tidak beriman menyangkut akhirat, yakni tidak percaya adanya hari kebangkitan setelah kematian, tidak juga pada surga dan neraka,mereka itu benar-benar dari jalan yang lurus itu, tetap bersih keras menyimpang dengan mantap. Padahal tidak ada jalan menuju kebahagian selain daripada jalan itu (Shihab, 2012: 398).

Artinya : Selain Allah; Maka tunjukkanlah kepada mereka jalan ke neraka."

Pada ayat di atas kata shirat di nisbakan kepada kata al-jahim . terlihat dinisbahkan kepada sesuatu yang tidak menyenangkan. Neraka Jahim adalah temapat penyiksaan dan penderitaan. Namun demikian ini adalah haq dan benar. Jangan lupa masuknya seseorang ke neraka merupakan penganiayaan atau tindakan yang tidak benar. Sama sekali tidak, di akhirat kelak, jalan yang ditunjukkan kepada para pendurhaka itu adalah jalan yang benar dan sesuai dengan pilihan mereka ketika hidup di dunia. Penggunaan kata shirat untuk menunjuk jalan ke neraka mengisyaratkan bahwa jalan tersebut sangat lebar, sebagaimana pengertian kebahasaan dari kata tersebut. Ini mengisyaratkan bahwa banyaknya pendurhaka menelusuri jalan itu serta mengisyaratkan juga bahwa jalan keneraka itu bukanlah jalan yang sempit dan kecil (Shihab, 2012: 231).

Artinya : "ketika mereka masuk (menemui) Daud lalu ia terkejut karena kedatangan) mereka. mereka berkata: "Janganlah kamu merasa takut; (Kami) adalah dua orang yang berperkara yang salah seorang dari Kami berbuat zalim kepada yang lain; Maka berilah keputusan antara Kami dengan adil dan janganlah kamu menyimpang dari kebenaran dan tunjukilah Kami ke jalan yang lurus."

Artinya: "(yaitu) jalan Allah yang Kepunyaan-Nya segala apa yang ada di langit dan apa yang ada di bumi. Ingatlah, bahwa kepada Allah-lah kembali semua urusan."

Penyebutan kata shirat Allah di awal itu berfungsi sebagai bukti ketepatan dan kesesuaian jalan yang lebar dan luas itu dengan para mukhallafin ( manusia). Ini kerena siapa yang menguasai segala sesuatu, tentulah dia mengetahui sifat dan cirinya, serta apa yang terbaik baginya. Dengan demikian jalan yang ditunjukkan buat mereka tentulah jalan terbaik dan mengantar mereka kepada kebahagiaan mereka (Shihab, 2012: 199). Pada Q. S Maryam : 43

Artinya : "Wahai bapakku, Sesungguhnya telah datang kepadaku sebahagian ilmu pengetahuan yang tidak datang kepadamu, Maka ikutilah Aku, niscaya aku akan menunjukkan kepadamu jalan yang lurus."

Ayat ini menjelaskan mengenai ajakan Nabi Ibrahim As kepada bapaknya agar mengikutinya berdasarkan pengetahuan yang diperolehnya. Disamping guna meyakinkan bapaknya tentang kebenaran ajakannya (Shihab, 2012: 462). Jadi 
pada intinya ajakan Nabi Ibrahim adalah jalan kebenaran yakni jalan yang lurus, yang beliau dapat berdasarkan pengetahuan dari Allah Swt. Jalan yang lurus pada ayat ini adalah ajalan agama, jalan Allah Swt.

Setelah beberapa penjelasan ayat di atas yang berkenaan dengan kata shirat, dapat ditarik suatu pemahaman bahwa kata shirat dalam tafsir al-misbah adalah yang berkenaan dengan jalan keyakinan, kebenaran yakni agama Islam ini semua tidak lepas dari kata shirat yang kebanyakan bersama dengan kata almustaqim dan hadiy, walaupun pada umumnya kata shirat merupakan jalan agama atau jalan kebenaran namun ada juga jalan keburukan, namun pada dasarnya kata shirat hanya menawarkan satu jalan.

Berikutnya kata sabil pada bab sebelumnya sudah dijelaskan bahwa kata sabil mempunyai bentuk jamak dan tunggal, untuk lebih mengetahui makna kata tersebut dalam tafsir al-misbah, maka penjelasannya sebagai berikut. Pertama Q. S Al-Baqarah : 108

Artinya : "Apakah kamu menghendaki untuk meminta kepada Rasul kamu seperti Bani Israil meminta kepada Musa pada jaman dahulu? dan Barangsiapa yang menukar iman dengan kekafiran, Maka sungguh orang itu telah sesat dari jalan yang lurus."

Dalam al-Qur'an terjemahan kata sawa' as-sabil di artikan dengan jalan yang lurus, akan tetapi dalam tafsir al-Misbah kata tersebut di maknai oleh M. Quraish Shihab sebagi jalan tengah. Jala tengan yang berarti tidak berada di pinggir jalan. Adapun jalan yang dipinggir dimaknai dengan jalan yang membuat manusia mudah terjerumus ke jurang. Dan itu bukan jalan yang disiapkan untuk pejalan dan bukan jalan yang mudah untuk dilalui (Shihab, 2012: 469). Jadi pada ayat ini jalan ditengah atau jalan lurus adalah jalan terbaik, sedangkan jalan dipinggir-pinggirnya bukan jalan dari Allah Swt. Berikutnya kata sabil yang terdapat dalam ( Q. S Al-Baqarah : 195)

Artinya : "Dan belanjakanlah (harta bendamu) di jalan Allah, dan janganlah kamu menjatuhkan dirimu sendiri ke dalam kebinasaan, dan berbuat baiklah, karena Sesungguhnya Allah menyukai orang-orang yang berbuat baik."

Ayat di atas menganjurkan untuk membelanjakan harta di jalan Allah Swt, dan Kalimat " $f i$ sabilillah" pada ayat tersebut bermakna jalan yang sangat terjaga. Dan hal ini memberikan kesan bahwa harta tersebut terjaga dan tidak akan hilang bahkan akan terus berkembang. Dan di tangan Allah Swt yang menjanjikan akan melipat gandakan setiap harta yang dinafkahkan dijalan-Nya. ( Q. S Al-Baqarah : 126). Jadi kata sabil pada ayat di atas dimakanai M. Quraish Shihab sebagai jalan yang terjaga (Shihab, 2012: 512).

Selanjutnya yang terdapat dalam ( Q. S An-Nisa : 75)

Artinya : "Dan Barangsiapa yang menentang Rasul sesudah jelas kebenaran baginya, dan mengikuti jalan yang bukan jalan orang-orang mukmin, Kami biarkan ia leluasa terhadap kesesatan yang telah dikuasainya itu dan Kami masukkan ia ke dalam Jahannam, dan Jahannam itu seburuk-buruk tempat kembali."

Pada ayat di atas kata sabil di awali terlebih dahulu dengan kata ghoiri yang bermakna bukan, jadi kata sabil pada konteks ayat di atas bermakna yang tidak baik, yakni bukan jalan orang mukmin, pada akhir ayat dijelaskan bahwa jalan tersebut mengarah ke neraka jahannam. Dalam tafsir al-misbah dijelaskan 
bahwa jalan yang bukan jalan orang-orang mukmin adalah kepercayaan, nilainilai yang tidak sejalan dengan nilai-nilai yang dianut oleh orang-orang mukmin, yang telah benar-benar beriman dengan baik. Ini berarti siapa saja yang mengikuti nilai-nilai Islam dalam keimanan dan kepercayaan dan mengikuti orang-orang kafir bukan dalam nilai-nilai yang bertentangan dengan ajaran Islam, katakanlah dalam bidang penerapan teknologi, dia tidak masuk yang diancam dalam ayat ini. (Shihab, 2012: 718). Pada ( Q. S Al-Maidah : 12)

Artinya : "Dan Sesungguhnya Allah telah mengambil Perjanjian (dari) Bani Israil dan telah Kami angkat diantara mereka 12 orang pemimpin dan Allah berfirman: "Sesungguhnya aku beserta kamu, Sesungguhnya jika kamu mendirikan shalat dan menunaikan zakat serta beriman kepada rasul-rasul-Ku dan kamu bantu mereka dan kamu pinjamkan kepada Allah pinjaman yang baik. Sesungguhnya aku akan menutupi dosa-dosamu. dan Sesungguhnya kamu akan Kumasukkan ke dalam surga yang mengalir air didalamnya sungai-sungai. Maka Barangsiapa yang kafir di antaramu sesudah itu, Sesungguhnya ia telah tersesat dari jalan yang lurus."

Pada ayat ini kata sabil diawali dengan kata "dholla sawaa" yang berarti telah tersesat dari jalan yang lurus. Maksud ayat di atas menyinggung orang-orang kafir yang memang daru awal sudah tersesat baik sesudah atau sebelum datangnya para Rasul. Hanya saja kerena belum datangnya para Rasul mereka masih ditoleransi kerena belum adanya perjanjian dan peringatan maka Allah Swt masih menunda Azab-Nya ( Q. S Al-Isra : 15), (Shihab, 2012: 60).

Pada Q. S Al-A'rof : 142 kata sabil bersama dengan kata mufsidin.

Artinya: "Dan telah Kami janjikan kepada Musa (memberikan Taurat) sesudah berlalu waktu tiga puluh malam, dan Kami sempurnakan jumlah malam itu dengan sepuluh (malam lagi), Maka sempurnalah waktu yang telah ditentukan Tuhannya empat puluh malam. dan berkata Musa kepada saudaranya Yaitu Harun: "Gantikanlah aku dalam (memimpin) kaumku, dan perbaikilah, dan janganlah kamu mengikuti jalan orang-orang yang membuat kerusakan".

Dalam ayat ini kata sabil bersama dengan kata mufsidin yakni orang-orang yang berbuat kerusakan. Pada ayat ini dalam tafsir al-misbah dijelaskan bahwa ayat ini mengandung pesan yang berarti jangan mengikuti jalan orang-orang yang berbuat kerusakan itu adalah tidak sekedar jangan berbuat kerusakan akan tetapi lebih dari itu yakni larangan berpartisipasi dalam kegiatan para perusak. Menurut ibnu Asyur pesan ini mengandung tiga hal, Pertama, larangan melakukan suatu pekerjaan buruk yang dilakukan oleh perusak. Kedua, larangan melakukan amal perusak, walaupun bukan pekerjaan yang biasa dilakukan. Ketiga, larangan bergaul dengan orang yang berbuat kerusakan. Larangan kedua dan ketiga merupakan bentuk kehati-hatian agar tidak menjerumus kepada yang pertama (Shihab, 2012: 284). lalu bagaimana dengan kata sabil dalam Q. S Al-A'rof : 146 berikut ini

Artinya: "Daku akan memalingkan orang-orang yang menyombongkan dirinya di muka bumi tanpa alasan yang benar dari tanda-tanda kekuasaan-Ku. mereka jika melihat tiap-tiap ayat(Ku), mereka tidak beriman kepadanya. dan jika mereka melihat jalan yang membawa kepada petunjuk, mereka tidak mau menempuhnya, tetapi jika mereka melihat jalan kesesatan, mereka terus memenempuhnya. yang demikian itu adalah karena mereka mendustakan ayat-ayat Kami dan mereka selalu lalai dari padanya." 
Pada ayat ini sangat menarik untuk dikupas lebih panjang, kerena dalam satu ayat ini ada dua kata sabil dengan tujuan yang berbeda. Pada ayat ini Allah Swt memalingkan manusia dari jalan kebenaran kejalan kesesatan, kenapa bisa demikian sangat tampak pertama Allah Swt memberikan dua jalan pilihan akan tetapi dia tidak menghendaki orang-orang yang menyombongkan diri memilih jalan kebenaran, namun Allah Swt membiarkan mereka pada jalan kesesatan. Itu semua kerena mereka mendustakan ayat-ayat Allah Swt. Menurut Asy-Sya'rawi dalam tafsir al-misbah bahwa Allah Swt akan memalingkan orang-orang yang sangat angkuh untuk melihat dengan pandangan I'tibar ayat-ayat Allah Swt, baik yang terhampar di alam raya, ayat-ayat al-Qur'an atau bukti-bukti yang dipaparkan para Rasul dalam bentuk mukjizat. Dengan demikian mereka tidak akan tersentuh dengan semua itu, mereka bisa beranggapak mukjizat tersebut adalah sihir atau fenomena alam (Shihab, 2012: 296).

Dalam paparan di atas jika ditarik suatu pemahaman bahwa kata sabil dalam tafsir al-misbah masih bermakna dua pilihan jalan yakni kebenaran dan kesesatan dalam kedua jalan tersebut ada jalan-jalan lainnya, misalnya jalan kesesatan bisa jalan orang-orang perusak, jalan orang-orang yang tidak mengetahui dan lain-lain begitu juga dengan jalan kebenaran, bisa jalan-jalan orang-orang mukmin dan lain-lain. Namun pada intinya sekalipun yang berhak menentukan manusia berada pada jalan yang benar atau salah tetap saja kata sabil sendiri memiliki makna suatu jalan usaha untuk mendapatkan jalan kebenaran.

Setelah kata shirat dan sabil terakhir kata thariq dalam tafsir al-misbah, akan dimulai pada Q. S An-Nisa :169

Artinya: "Kecuali jalan ke neraka Jahannam; mereka kekal di dalamnya selamalamanya. dan yang demikian itu adalah mudah bagi Allah."

Sebenarnya untuk memahami makna ayat di atas akan lebih baik jika mengetahui ayat sebelumnya yakni Q. S An-Nisa : 167-168. Pada kedua ayat tersebut dijelaskan bahwa orang-orang yang menghalangi dari jalan Allah Swt benar-benar berada pada jalan yang sesat, dan Allah Swt tidak akan mengantar mereka kesuatu jalan kecuali ke neraka jahannam. Jadi jika sudah dijabarkan ayat sebelumnya bisa dipahami bahwa jalan ke neraka jahannam untuk orang-orang yang menghalangi jalan-jalan Allah Swt. Dalam tafsir al-misbah menjelaskan bahwa makna dari Allah Swt tidak akan mengantarkan mereka kejalan, kecuali ke neraka jahannam, mengandung suatu makna bahwa Allah Swt tidak akan mengantarkan mereka ke jalan kebahagiaan yakni jalan yang lurus ( Q. S Alfatihah : 6) (Shihab, 2012: 284). Berikutnya terdapat juga dalam Q. S Al-Ahqof : 30

Artinya : "Mereka berkata: "Hai kaum Kami, Sesungguhnya Kami telah mendengarkan kitab (Al Quran) yang telah diturunkan sesudah Musa yang membenarkan Kitab-Kitab yang sebelumnya lagi memimpin kepada kebenaran dan kepada jalan yang lurus.

Pada ayat di atas tampak jelas kata thariq digunakan untuk menunjukkan pada suatu ajaran atau agama yang benar, sekali lagi bahwa kata al-mustaqim tidak pernah lepas dari kata ihdiy ini menunjukkan bahwa orang-orang yang berada pada jalan yang luru hanya orang-orang yang mendapatkan hidayah. Baik kata yang digunakan shirat maupun thariq, dan dalam kata subul jamal dari kata sabil. 
Artinya : "Sesungguhnya orang-orang yang kafir dan melakukan kezaliman, Allah sekali-kali tidak akan mengampuni (dosa) mereka dan tidak (pula) akan menunjukkan jalan kepada mereka"

Kata thariq pada ayat di atas bermakna petunjuk agama, seperti biasanya di dahului dengan kata hadiy sama hal nya dengan kata ihdiy as-shirat almustaqim. Jalan yang lurus, jalan kebenaran yakni agama Islam. berbeda.

Pada Q. S Al-Mu'minun : 17, kata thariq mempunyai makna yang

Artinya : "Dan Sesungguhnya Kami telah menciptakan di atas kamu tujuh buah jalan (tujuh buah langit); dan Kami tidaklah lengah terhadap ciptaan (kami)."

Pada ayat ini sangat menarik, ketika kata thariq yang jamaknya thoroiq, diartikan dengan kata jalan atau lintasan pada langit. Jadi kata thariq pada ayat ini sudah diluar konteks petunjuk atau hidayah akan tetapi sudah mengarah kepada yang lebih umum. Dalam tafsir al-misbah Ibnu A'syur memahami kata tersebut dalam arti jalan. Namun menurutnya yang di maksud adalah garis yang dibuat manusia sebagai imajinasi dari tempat peredaran tujuh planet. Dan ayat tersebut seakan-akan menyatakan bahwa "dan kami telah menciptakan di atas kamu planet-planet dan dengan jalan-jalannya ( lintasan )" (Shihab, 2012: 243).

Artinya : "Dan Sesungguhnya di antara Kami ada orang-orang yang saleh dan di antara Kami ada (pula) yang tidak demikian halnya. adalah Kami menempuh jalan yang berbeda-beda."

Pada Q. S Al-Jin : 11 ini, kata thoroiq qidada atau jalan yang berbeda bermakna perselisihan dan perbedaan pandangan satu sama lain (Shihab, 2012: 380).

Kata thariq dalam Q. S Thoha: 108

Artinya : "Kami lebih mengetahui apa yang mereka katakan, ketika berkata orang yang paling Lurus jalannya di antara mereka: "Kamu tidak berdiam (di dunia), melainkan hanyalah sehari saja".

Menurut Ibnu A'syur kalimat yang paling lurus jalannya bukan dalam arti yang paling dekat kepada kebenaran, tetapi yang paling pandai membuat dalih adalah yang berkata : " kamu tidak tinggal di kubur melainkan hanyalah sehari saja " . atau bisa juga ejekan atau cemoohan bagi orang-orang kafir, (Shihab, 2012: 669).

Artinya : "Dan bahwasanya: Jikalau mereka tetap berjalan Lurus di atas jalan itu (agama Islam), benar-benar Kami akan memberi minum kepada mereka air yang segar (rezki yang banyak)."

Pada Q. S Al-Jin : 16 ini sudah sangat jelas maksud dari istiqomah pada jalan yang lurus tersebut adalah agama Islam, (Shihab, 2012: 383). Dari penjabaran kata thariq di atas dapat ditarik suatu pemahaman bahwa kata thariq masih sangat umum sekali dalam arti bisa digunakan dalam keadaan apapun, bisa bermakna jalan yang sesungguhnya, lintasan, atau bisa juga petunjuk jalan kebenaran (agama Islam)

\section{Simpulan}

Kata shiraat dalam tafsir al-Misbah lebih khusus bermakna jalan agama yakni jalan kebenaran, dan hanya bisa diperoleh oleh manusia dengan kehendak Allah Swt, kata sabil bermakna jalan agama juga akan tetapi memiliki dua jalan, kebaikan atau keburukan, dan untuk mendapatkan jalan kebaikan atau kebenaran 
harus adanya usaha manusia. Adapun kata thariq makna jalan yang masih umum bisa jalan agama, jalan raya atau jalan-jalan lainnya, namun jika dikaitkan dalam konteks jalan agama dia masih bisa sama dengan sabil, bisa digunakan untuk kebaikan atau kejahatan. Jadi bisa ditarik suatu rumusan khusus dari umum ke khusus, susunan maknanya mulai dari thariq, sabil dan shiraat, maka bisa ditarik suatu kesimpulan bahwa baik thariq maupun sabil semuanya akan bermuara kepada shiraat sebagai jalan terakir dan jalan kebenaran. 


\section{DAFTAR PUSTAKA}

Abdullah, Maskuri. 2001. Pluralisme Agama dan Kerukunan dalam Keagamaan, Jakarta: Buku Kompas.

Tim Penterjemah al-Qur'an, 2012. Departemen Agama RI, al-Qur'an dan Terjemahannya, Jakarta: Sinergi Pustaka Indonesia.

Abdul. Al-hayy Al-Farmawi, 1996. Metode Tafsir Mawdhu'iy Suatu Pengantar, Jakarta: Rajawali Pers.

Abdul Baqy, Muhammad Fu'ad. 1981. al-Mu'jam al-Mufahrosy Li al-Fadz alQur'an al-Karim, Beirut: Darul Fikri.

Abdul Shabur Syahin, 2005. Difa' Dhidd Hujumat al-Istiyraq, Tarikh Al-Qur'an, diterjemahkan oleh, Khirul Amru Harahan dan Akhmad Faozan, Ketika Al-Qur'an Butuh Pembelaan, Jakarta: Erlangga.

Asy-Sya'rawi, Mutawalli, 2004. Mu'jizat Ar-Rasul, Diterjemahkan Oleh Ahmad Zubaidi, Mu'jizat Rasulullah Saw, Jakarta: Al-Mawardi Prima.

Mujieb, M. Abdul, Dkk, 2009. Ensiklopedia Tasawwuf Imam Al-Ghazali, Bandung: Mizan.

Mustafa Al-Maraghi, 1993. Ahmad, Tafsir Al-Maraghi Juz 29, Cet Ke-2 Semarang: Karya Toha Putra.

Setiawan, Nurcholis, 2005. Al-Qur'an Kitab Sastra Terbesar, Yogyakarta: eLSAQ Press.

Shihab, M. Quraish , 2008. Lentera Al-Qur'an, Cet Ke-2, Jakarta: Mizan.

-------, 2009. Membumikan Al-Qur'an Cet Ke-3, Bandung: Mizan.

-------, 2007. Tafsir Al-Misbah, Cet Ke-8 Jakarta: Lentera Hati

Syaltut, Muhammad, 1989. Tafsir Al-Qur'anul Karim Cet Ke-1, Bandung: Diponegoro. 